\title{
The WEST project: Validation program for WEST tungsten coated plasma facing components
}

\author{
M. Richou ${ }^{\mathrm{a}}$, M. Missirlian ${ }^{\mathrm{a}}$, E. Tsitrone ${ }^{\mathrm{a}}$, J. Bucalossi ${ }^{\mathrm{a}}$, C. Desgranges ${ }^{\mathrm{a}}$, M. Firdaouss ${ }^{\mathrm{a}}$, D. \\ Guilhem $^{\mathrm{a}}$, H. Greuner ${ }^{\mathrm{b}}$, C. Hernandez ${ }^{\mathrm{a}}$, M. Lipa ${ }^{\mathrm{a}}$, G. Pintsuk ${ }^{\mathrm{c}}$, F. Samaille ${ }^{\mathrm{a}}$ \\ ${ }^{a}$ CEA, IRFM, F-13108 Saint-Paul-Lez-Durance, France \\ ${ }^{\mathrm{b}}$ Max-Planck-Institut for Plasma Physics, Boltzmannstr. 2, 85748 Garching, Germany \\ ${ }^{\text {c }}$ Forschungszentrum Juelich, 52425 Juelich, Germany
}

E-mail: marianne.richou@cea.fr

\begin{abstract}
The W-for tungsten-Environment in Steady-state Tokamak (WEST) project is based on an upgrade of the Tore Supra tokamak from a carbon limiter to an X-point divertor device. A new set of actively cooled tungsten coated plasma facing components (PFC) will cover a part of the vessel to provide a fully metallic environment. This paper deals with the validation program performed for tungsten coatings $(\geq 15 \mu \mathrm{m})$ on a CuCrZr substrate. The first step was dedicated to the qualification under high heat flux tests of the coating on small inertially cooled samples. To study the thermal behaviour and the non-uniformity, the second step was dedicated to the validation of the coating on large inertially cooled samples with geometry and shape $(540 \times 120 \mathrm{~mm})$ representative of the WEST coated components. The last step was dedicated to the optimization of the coating and to the HHF tests up to $10.5 \mathrm{MW} / \mathrm{m}^{2}$ on relevant coated actively cooled prototypes. Non-uniformity and thickness of the coating (15 $\mu \mathrm{m}$ and $30 \mu \mathrm{m})$ correspond to specifications. As no delamination was observed, coatings of 15 and $30 \mu \mathrm{m}$ were qualified with regard to their application on WEST coated components. In order to decrease the risk of coating delamination under thermal loading, it was decided to cover the upper divertor and baffle targets with the thinnest coating option of $15 \mu \mathrm{m}$.
\end{abstract}

\section{Introduction}

The WEST (W -for tungsten- Environment in Steady-state Tokamak) project is targeted to minimize risks for ITER full tungsten divertor procurement and operation [1]. It is based on an upgrade of the Tore Supra tokamak from a carbon limiter to an X-point divertor device, while taking advantage of its long discharge capability in the range of minutes. ITER-like actively cooled tungsten targets (monoblocks) will be integrated in the lower divertor and a new set of actively cooled tungsten coated plasma facing components (PFC) (e.g. upper divertor, baffle, protection against Vertical Displacement Events (VDE) and ripple losses) will cover parts of the vessel to provide a fully metallic environment (Fig. 1). This project will deal with the installation and testing of ITER-like actively cooled components [2]. The upper divertor target and the baffle are actively cooled PFCs. They are based on a Copper-Chromium-Zirconium (CuCrZr) heat sink concept, coated with tungsten. Since 2012, coating developments have been carried out for these components. This paper deals with the validation program performed for tungsten coatings $(\geq 15 \mu \mathrm{m})$ on a CuCrZr substrate. It first describes the actively cooled plasma facing components involved, in terms of geometry and thermal loading specifications. Then, the main features and expected characteristics of this tungsten coating are presented. The last part is dedicated to the validation program of the $\mathrm{W}$ coating, mainly based on its thermal behavior assessment under high heat flux testing with regard to plasma facing components specifications. 


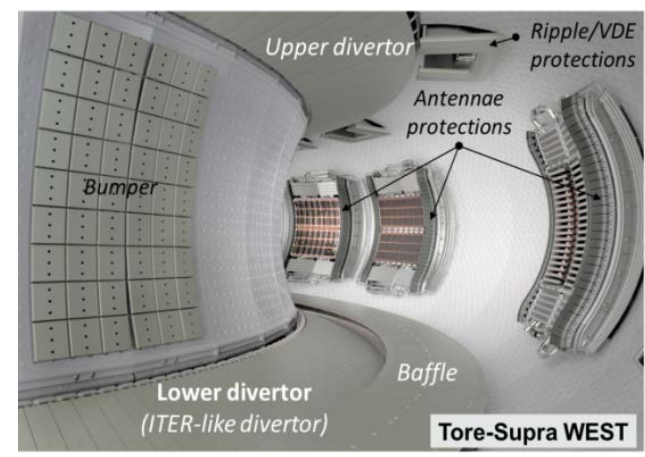

Fig. 1: Tore Supra in the WEST configuration, showing the main plasma facing components

\section{Upper divertor and baffle targets}

\subsection{Geometry}

The WEST upper divertor and baffle targets consist of 12 independent toroidal sectors of 30 [3]. Each sector is composed of 38 copper-Plasma Facing Units (so called Cu-PFU in this paper) for the upper divertor target [4] and of 12 baffle units for the baffle target. These components are actively cooled (inlet pressure and coolant temperature are set to $33 \mathrm{bar}$ and $70^{\circ} \mathrm{C}$, respectively and the coolant velocity is $5 \mathrm{~m} / \mathrm{s}$ ). Each of these components is composed of a CuCrZr heat sink. CuCrZr is chosen for its advantages with regard to its thermal and mechanical properties. The heat loaded surface of these components is coated with a $\mathrm{W}$ layer [5]. For better adhesion of the $\mathrm{W}$ coating, a chamfer $(\mathrm{R}=2 \mathrm{~mm})$ is machined along the length on the component edge (Fig. 2) The total Cu-PFU dimensions are $~ 540 \times 32 \times 42 \mathrm{~mm}$, the surface to be coated is $\sim 449 \times 32 \mathrm{~mm}$ (Fig. 2). The baffle unit dimensions are $\sim 405 \times 121 \times 18 \mathrm{~mm}$, the surface to be coated is $\sim 405 \times 121 \mathrm{~mm}$ (Fig. 2).

\section{a) Cu-PFU}

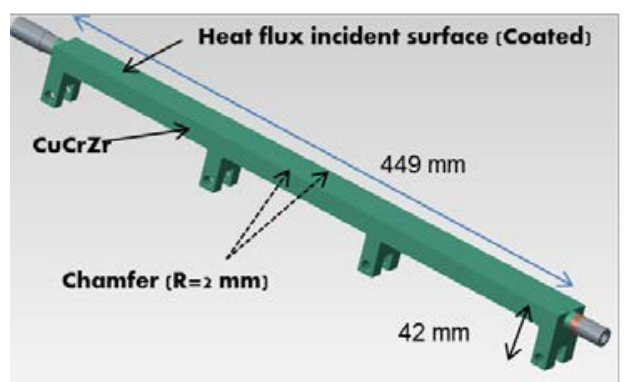

b) Baffle Unit

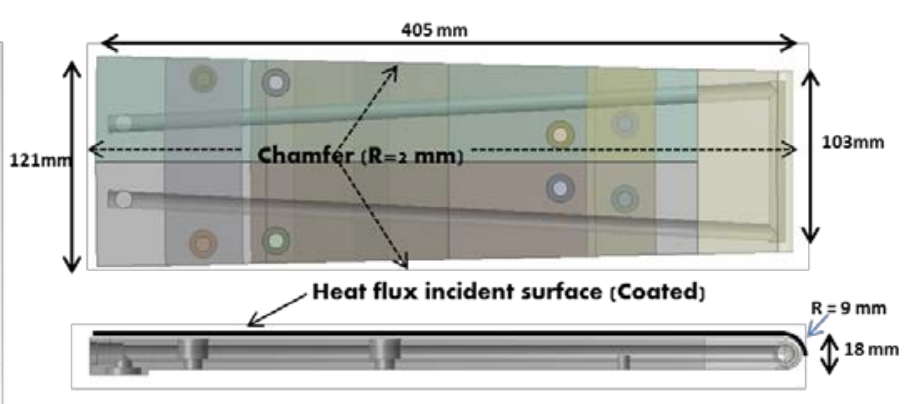

Fig. 2: Geometries of a) Cu-PFU and b) baffle unit

\subsection{Specification}

The upper divertor target is designed to exhaust in total $4 \mathrm{MW}$ of conducted power in steady state with a maximum local heat load of $8 \mathrm{MW} / \mathrm{m}^{2}$ [4]. The baffle target must be able to extract in total $3 \mathrm{MW}$ in steady state, in order to cope with the plasma conducted power, localized ion losses or fast electrons generated by the RF heating systems as well as radiation losses. The baffle target must be able to handle locally heat loads up to $3 \mathrm{MW} / \mathrm{m}^{2}$ near the leading edge region (i.e. round edge shape region) in steady state. Components have also to sustain transient thermal loads $\left(\sim 400 \mathrm{~kJ} / \mathrm{m}^{2}\right)$ [6] as the one occurring during WEST Edge Localised Modes (ELMs).

One of the constraints of these components, for cumulated long lasting plasma operation, is the maximum allowable surface temperature of $450^{\circ} \mathrm{C}$ for $\mathrm{CuCrZr}$ substrate. This temperature has been defined in order to keep the mechanical properties during operation life time [7]. However, during transient thermal loads, a surface temperature up to $600^{\circ} \mathrm{C}$ is tolerated.

\subsection{Coating characteristics}

The $\mathrm{W}$ coating thickness has been defined with regard to component specification and coating manufacturing feasibility. With respect to the component specification, the tungsten coating thickness is a compromise between the coating thermal performance (thin coatings to avoid delamination under thermal stresses) and the coating lifetime (thick coatings to handle plasma erosion). In the case of the upper divertor and 
the baffle, the emphasis has been set on the performance under thermal stress, so that thin coatings (between 15 and $50 \mu \mathrm{m}$ ) have been investigated during the validation process.

Rough estimates of the coating lifetime can be derived from the plasma edge simulations performed in [8] with the SolEdge2D-EIRENE code [9] [10]. Tungsten erosion both from the deuterium plasma and deuterium charge exchange atoms is calculated around the main chamber for typical discharge conditions in a lower single null configuration. A maximum gross erosion of $1.510^{-3} \mu \mathrm{m} / \mathrm{s}$ is found on the lower divertor in the strike point area, while it is an order of magnitude lower for the upper divertor. For the baffle, the maximum is found to be around $510^{-4} \mu \mathrm{m} / \mathrm{s}$ in the leading edge area. However, net erosion is expected to be significantly lower (typically around $10^{-4} \mu \mathrm{m} / \mathrm{s}$ for the lower divertor and $510^{-5} \mu \mathrm{m} / \mathrm{s}$ for the baffle), as prompt redeposition will play a significant role. For a $15 \mu \mathrm{m}$ coating, this would correspond to a lifetime of several hours of plasma operation if gross erosion is taken as an upper envelop, and several tens of hours if net erosion is considered. In this last case, this would be sufficient for several years of experimental campaigns in WEST. However, it should be noted that the numbers quoted here are subject to large uncertainties, as the impact of light impurities (oxygen, carbon, etc) or ELMs, which are known to play a large role in W dust production in AUG or JET [11], is not taken into account in the present modelling. The estimated erosion rates here are however consistent with experimental findings in AUG, showing a net erosion of $1.210^{-4} \mu \mathrm{m} / \mathrm{s}$ in the divertor strike point area [11].

In order to avoid a difference of thermal behavior, non-uniformity of the deposit thickness has to be as low as possible (i.e. in the range of $\pm 5 \mu \mathrm{m}$ around the specified nominal $\mathrm{W}$ coating thickness). During the coating series production, nominal tungsten thickness will be defined at $+5 \mu \mathrm{m} /-0 \mu \mathrm{m}$ around specified coating thickness. With regard to plasma operation, impurities $(\mathrm{C}, \mathrm{O})$ concentration in coatings has to be as low as possible. In this study, the admitted concentration is $5 \%$ at.

\section{Coating technique and validation}

\subsection{Description of PVD coating technique}

Considering the specified coating thickness (15 $\mu \mathrm{m}$ to $50 \mu \mathrm{m}$ ), Physical Vapour Deposition (PVD) was studied for the realization of the $\mathrm{W}$ coating. $\mathrm{W}$ coatings were made by magnetron cathodic sputtering process in a vacuum chamber. The volume of this vacuum chamber is $0.6 \times 0.6 \times 0.6 \mathrm{~m}^{3}$. The coating on rounded edges and on Cu-PFU length $(\sim 449 \mathrm{~mm}$ ) required a development in order to define adapted number and position of the cathodes in the PVD chamber. Finally, cathodes were placed facing each other on the walls of the reactor while the samples are placed on a rotating substrate.

Coating process is composed of several phases. The cleaning of substrate and tungsten targets with argon ions is the most important step to ensure the adherence of the coating. This phase consists in the removal of the oxides and particles from the surface to be coated.

The global coating process has been consequently adapted so that coating adherence under heat loads and coating homogeneity are ensured for both the heat flux incident flat surface and the rounded edge shape. In this configuration, no interlayer is needed between $\mathrm{W}$ coating and CuCrZr substrate.

\subsection{Validation program}

The thermal behaviour of the coating during plasma operation depends mainly on its temperature but also on the temperature field in the coating itself. The temperature field is dependent on the heat loading on incident coated surface and on geometry/cooling of studied components. In order to assess thermal behaviour of the coating, a validation program has been performed. This program, divided in several phases, was mainly based on High Heat Flux (HHF) tests. The first phase was dedicated to HHF tests on small inertially cooled samples. The aim of this phase was to test the adherence of the coating onto $\mathrm{CuCrZr}$ substrate under relevant temperatures (between $450^{\circ} \mathrm{C}$ and $600^{\circ} \mathrm{C}$ ), but not under relevant heat load. The objective of this phase was to provide a rough estimation, on a limited number of samples, about the thermal behaviour of samples equipped with the coating with needed specifications. The second step was dedicated to the validation of the coating on large inertially cooled samples with geometry and shape representative of the WEST coated components. The aim of the last step was to test prototypes with tungsten optimized coating under relevant WEST heat loading. High cycle fatigue experiments were excluded due to the time constraints of the WEST project. Therefore, a program for low-cycle fatigue experiments (130-500 cycles) was proposed. The number of cycles was chosen to be roughly the same as the one used for the qualification program for the W coating of JET ITER-like wall [12]. 


\subsubsection{Small scale inertially cooled samples}

W coatings were developed and processed on small CuCrZr samples (diameter $30 \mathrm{~mm}$, thickness $4 \mathrm{~mm}$ ). HHF tests were performed in the neutral beam facility GLADIS at IPP Garching [13], on 4 small samples (2 samples with a coating thickness of $15 \mu \mathrm{m}$, and 2 samples with a coating thickness of $50 \mu \mathrm{m})$. Condition of Gaussian heat load repartition is recalled in [13]. The loading was performed to achieve a surface temperature of $450^{\circ} \mathrm{C}\left( \pm 50^{\circ} \mathrm{C}\right)$, a shutdown of the beam, a resting period for allowing the sample temperature to decrease to room temperature and a repetition of the before mentioned steps for 130 cycles. Due to the low coating thickness with regard to the total thickness of the tested samples, thermal gradient in the coating is negligible compared to the thermal gradient in the sample itself. Due to the adherence of the coating on the CuCrZr substrate, thermal resistance is negligible at this interface. Consequently, the maximum surface temperature is considered as the same as the maximum temperature in CuCrZr. The absorbed heat flux in these experiments was $\sim 2.5 \mathrm{MW} / \mathrm{m}^{2}$ for a loading time of $3 \mathrm{~s}$. The two samples with $15 \mu \mathrm{m}$ coating thickness and one sample with $50 \mu \mathrm{m}$ coating thickness survived such a thermal solicitation without delamination. However, the second sample with $50 \mu \mathrm{m}$ coating thickness delaminated after the second cycle. As consequence, the $50 \mu \mathrm{m}$ thick coating was abandoned and a coating of $30 \mu \mathrm{m}$ was developed.

Additional HHF tests were performed in order to increase the number of cycle to 500 cycles and to load small samples at higher surface temperature relevant to transient heat loads $\left(600^{\circ} \mathrm{C}\right)$. These tests were performed on two small samples ( 1 sample of $15 \mu \mathrm{m}$, and 1 sample of $30 \mu \mathrm{m}$ ) with the electron beam facility JUDITH 2 at Forschungszentrum Jülich (Germany). Condition of homogeneous heat load repartition is recalled in [14]. The loading time, loaded heat flux and the number of cycles are presented in Table 1. Samples were tested up to 5.9 $\mathrm{MW} / \mathrm{m}^{2}$. As no delamination was observed, the $15 \mu \mathrm{m}$ and $30 \mu \mathrm{m}$ coating thicknesses were validated for small scale inertially cooled samples.

\begin{tabular}{|c|c|c|c|c|c|c|}
\hline \multirow{3}{*}{ Samples } & $\begin{array}{c}\text { Thickness } \\
\text { (Number of } \\
\text { tested } \\
\text { samples) }\end{array}$ & $\begin{array}{c}\text { Number of } \\
\text { cycles }\end{array}$ & $\begin{array}{c}\text { Maximum } \\
\text { surface } \\
\text { temperature } \\
\left({ }^{\circ} \mathrm{C}\right)\end{array}$ & $\begin{array}{c}\text { Absorbed heat flux } \\
(\mathrm{MW} / \mathrm{m} 2)\end{array}$ & $\begin{array}{c}\text { Loading time (s)/ } \\
\text { Cooling time (s) }\end{array}$ & Result \\
\hline \multirow{3}{*}{ Small } & $\begin{array}{c}15 \mu \mathrm{m}(2), \\
50 \mu \mathrm{m}(2)\end{array}$ & 130 & $450^{\circ} \mathrm{C}$ & $2.5 \pm 5 \%$ & $3 \mathrm{~s} / 20 \mathrm{~s}$ & $\begin{array}{c}1 \text { sample }(50 \mu \mathrm{m}) \\
\text { delaminates }\end{array}$ \\
\cline { 2 - 7 } & $\begin{array}{c}15 \mu \mathrm{m}(1), \\
30 \mu \mathrm{m}(1)\end{array}$ & 500 & $450^{\circ} \mathrm{C}$ & $4.9 \pm 10 \%$ & $2 \mathrm{~s} / 20 \mathrm{~s}$ & No delamination \\
\cline { 2 - 7 } & $15 \mu \mathrm{m}(1)$ & 130 & $600^{\circ} \mathrm{C}$ & $5.9 \pm 10 \%$ & $2 \mathrm{~s} / 30 \mathrm{~s}$ & No delamination \\
\hline \multirow{2}{*}{ Large } & $30 \mu \mathrm{m}(1)$ & 130 & $450^{\circ} \mathrm{C}$ & $3.4 \pm 20 \%$ & $3 \mathrm{~s} / 180 \mathrm{~s}$ & No delamination \\
\cline { 2 - 7 } & & $450^{\circ} \mathrm{C}$ & $1.5 \pm 5 \%$ & $8 \mathrm{~s} / 180 \mathrm{~s}$ & No delamination \\
\hline
\end{tabular}

Table 1 : Experimental data of High Heat Flux tests performed on small and large samples

\subsubsection{Large scale inertially cooled samples}

Then, coatings of $15 \mu \mathrm{m}$ and $30 \mu \mathrm{m}$ were realized on two large inertially cooled components (540x120x16 mm) with leading edge shape (Fig. 3). This geometry is representative of the upper divertor length as well as the baffle regarding the width and the leading edge shape. The coating thickness along the component length and the round edge shape was measured. For these coatings a non-uniformity of $\pm 5 \mu \mathrm{m}$ is measured. This result is in agreement with required specification (see section 2.3).

Large inertially cooled components were tested under HHF tests at JUDITH 2. The loading time, loaded heat flux and the number of cycles are presented in Table 1. Depending on the loaded time, components were tested up to $3.4 \mathrm{MW} / \mathrm{m}^{2}$. Independently of loading time, no delamination or surface increase temperature was observed during HHF tests. Surface micrographs of these coating are presented in Fig. 4a. Open pores, observable from the top surface, indicate that the coating is not fully dense ( $95 \%$ ) [15]. For this reason the last step of the development consisted in: optimizing the coating density, covering upper divertor prototypes with optimized coating and HHF testing of coated prototypes under relevant WEST heat loading. 


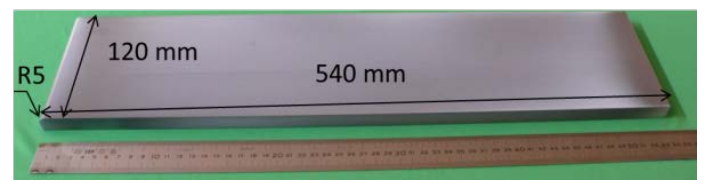

Fig. 3 : Size and shape of large inertially cooled component

a) BEFORE OPTIMISATION
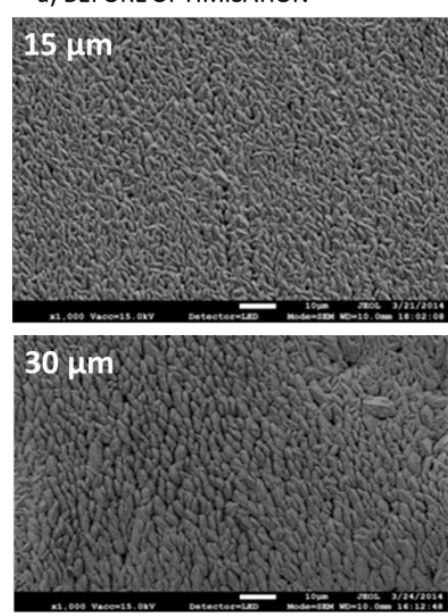

b) AFTER OPTIMISATION
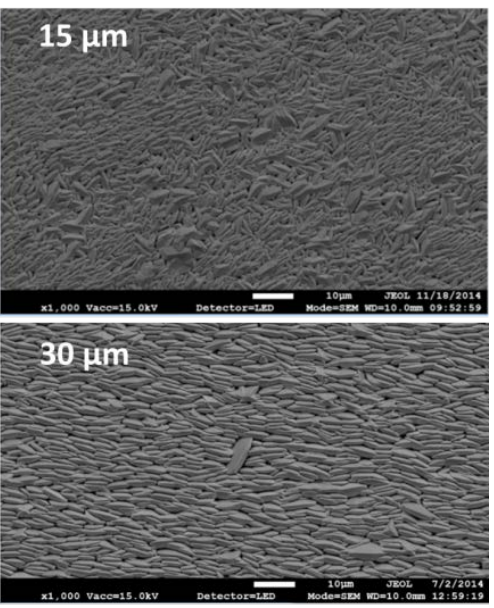

Fig. 4 : Coatings surface micrographs a) before and b) after coating optimization for $15 \mu \mathrm{m}$ and $30 \mu \mathrm{m}$

\subsubsection{Optimization of the coating density}

Optimization of the coating density consisted in defining the adapted coating process conditions (pressure and duration) for targets and substrate cleaning. If the density is increased, the thermal conductivity of the coating is increased, however the stress at the interface between coating and CuCrZr substrate is increased, so that probability of coating delamination increases. Coating process conditions were defined as a compromise between: obtaining dense coating and obtaining a coating able to sustain the WEST heat loads.

For the optimized coating, fewer pores are visible from the surface compared to the non-optimized coating, (Fig. 4b). The coating cross section presents a columnar growth aspect (Fig. 5). Coating density was not measured; however, considering micrographs, one can say that density was improved with optimization. Coating thicknesses of $18 \mu \mathrm{m}$ and $28 \mu \mathrm{m}$ are obtained for the specified $15 \mu \mathrm{m}$ and $30 \mu \mathrm{m}$ processes, respectively. Obtained nominal thicknesses are $\pm 3 \mu \mathrm{m}$ within thickness specification.

\subsubsection{Prototypes HHF testing (Steady state and transient heat loads)}

In order to evaluate the thermo-mechanical behavior under the temperature distribution relevant to the WEST operation condition, two actively cooled Cu-PFU prototypes (with $\mathrm{W}$ coating thickness $15 \mu \mathrm{m}$ and 30 $\mu \mathrm{m})$, were HHF tested in the GLADIS facility. The heat flux distribution is a Gaussian profile in $\mathrm{x}$ and $\mathrm{y}$ direction. Applied hydraulic conditions were: $0.4 \mathrm{l} / \mathrm{s}$ (corresponding to a water velocity of $\sim 8 \mathrm{~m} / \mathrm{s}$ ), 10 bar and $20{ }^{\circ} \mathrm{C}$. Prototypes were loaded by a repetitive cycling: $\sim 60$ cycles at $8 \mathrm{MW} / \mathrm{m}^{2}$ followed by $\sim 10$ cycles at 10.5 $\mathrm{MW} / \mathrm{m}^{2}$. At a maximum heat flux of $8 \mathrm{MW} / \mathrm{m}^{2}$ and $10.5 \mathrm{MW} / \mathrm{m}^{2}$, a maximum surface temperature of $\sim 445{ }^{\circ} \mathrm{C}$ and $\sim 500{ }^{\circ} \mathrm{C}$, respectively, were obtained by infrared measurements (Table 2). This result is in agreement with the predictions provided by finite element calculations performed for similar heat load conditions showing hence a good thermal behavior of both tested components, and with the expected thermal exhaust capability. No visible delamination is observed after steady state thermal loading even by observations with stereo microscope at 50x magnification.

Then, transient thermal loads $\left(400 \mathrm{~kJ} / \mathrm{m}^{2}\right)$, similar to those expected during WEST Edge Localised Modes (ELMs) were also applied for the prototype covered with $15 \mu \mathrm{m}$ tungsten coating. To simulate these loads with GLADIS neutral beam, a maximum heat flux of $20 \mathrm{MW} / \mathrm{m}^{2}$ was applied during $\mathrm{t}=20 \mathrm{~ms}$. The beam is then stopped during $40 \mathrm{~ms}$. ELM pulses are repeated during $10 \mathrm{~s}$. Then the beam is stopped during $60 \mathrm{~s}$. This sequence is defined to one cycle. 20 cycles were applied. After this sequence, no delamination was observed. 
Considering the fact that no delamination was observed, $15 \mu \mathrm{m}$ and $30 \mu \mathrm{m}$ tungsten coating thicknesses were qualified. However, in WEST, coatings will be loaded for a significantly higher number of cycles than the one tested during this validation program. In order to decrease the risk of delamination driven by repeated thermal stresses in the coating, it was decided to cover the upper divertor and baffle targets with the thinnest coating option $(15 \mu \mathrm{m})$, as it has been calculated to be sufficient to ensure a reasonable lifetime during plasma operation. Indeed, it has been shown that thicker coatings are prone to delamination. This can lead to operational issues limiting plasma performance (see [16] [17] [18] as shown in analysis for the coatings of the JET ITER Like Wall, although on a carbon substrate).
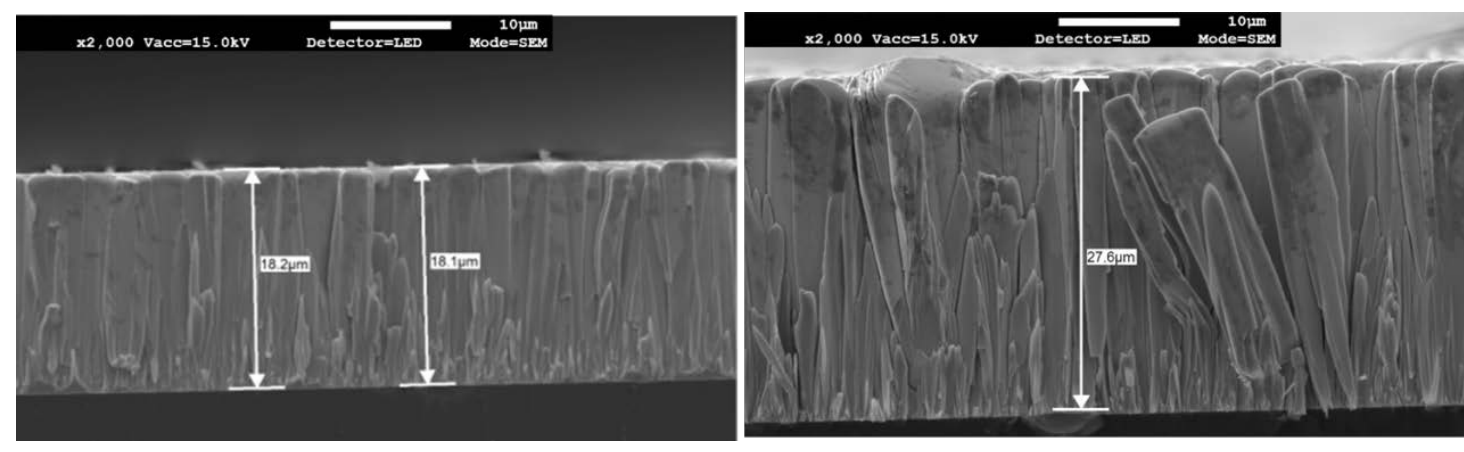

Fig. 5 : Micrographs of coating thicknesses $(15 \mu \mathrm{m}$ and $30 \mu \mathrm{m})$

\begin{tabular}{|c|c|c|c|}
\hline $\begin{array}{c}\text { Thickness } \\
\text { (\# of prototypes) }\end{array}$ & Absorbed heat Flux $\left(\mathrm{MW} / \mathrm{m}^{2}\right)$ & $\begin{array}{c}\text { Maximum surface } \\
\text { temperature }\left({ }^{\circ} \mathrm{C}\right)\end{array}$ & Result \\
\hline $\begin{array}{c}15 \mu \mathrm{m}(1) \\
30 \mu \mathrm{m} \mathrm{(1)}\end{array}$ & $8 \mathrm{MW} \cdot \mathrm{m}^{-2}$ & $\sim 445$ & Qualified \\
\cline { 2 - 4 } & $10.5 \mathrm{MW} \cdot \mathrm{m}^{-2}$ & $\sim 500$ & Qualified \\
\hline
\end{tabular}

Table 2: Experimental results for Cu-PFU prototypes under HHF tests

\section{Conclusion and perspectives}

Since 2012, coating developments on CuCrZr substrate have been carried out in order to qualify a tungsten coating suitable for WEST coated actively cooled plasma facing components such as the baffle unit and upper divertor component. The validation program was divided in several phases. The first step enabled to assess the relevant thickness. The second step enabled to validate the coating process with regard to its uniformity and its thermal behaviour under HHF tests. The last step was dedicated to the HHF tests up to $10.5 \mathrm{MW} / \mathrm{m}^{2}$ on relevant coated actively cooled prototypes. Thermal behaviour, non-uniformity and thickness of the coating (15 $\mu \mathrm{m}$ and $30 \mu \mathrm{m}$ ) correspond to specifications. As no delamination was observed, coatings of $15 \mu \mathrm{m}$ and $30 \mu \mathrm{m}$ were validated with regard to their application on upper divertor component and baffle unit. Within this validation program, the number of tested samples and components is low. This study is, consequently, not statistically representative. In order to decrease the risk of coating delamination under thermal loads, it was decided to cover the upper divertor and baffle targets with the thinnest coating option of $15 \mu \mathrm{m}$. Further tests will be performed on this coating to assess the number of fatigue cycles they can undergo at the nominal heat flux specified by WEST operation. In order to avoid starting from scratch after possible tungsten delamination, coating reparation process is also under development.

\section{References}

[1] Bucalossi J et al. 2014 Fusion Eng. Des. 89 907-912

[2] Lei Cao, Zibo Zhou, Damao Yao 2015 Journal of Fusion Energy DOI 10.1007/s10894-015-9951-2

[3] Missirlian M et al. 2014 Fusion Eng. Des. 89 1048-1053.

[4] Richou M et al. 2015 Fusion Eng. Des. In press

[5] Hernandez C et al. 2015 Phys. Scr. (This conference)

[6] Bourdelle C et al. 2015 Nucl. Fusion 55 doi:10.1088/0029-5515/55/6/063017

[7] ITER, Materials Properties Handbook (MPH), 2011 (internal project document) 
[8] Bufferand H et al 2015 Nucl. Fusion 55 053025. doi:10.1088/0029-5515/55/5/053025

[9] Bufferand H et al. $2013 \mathrm{~J}$. of Nucl. Materials 438 S445-448

[10] Bufferand H. et al. 2014 Contrib. Plasma Phys. 54378

[11] Dux R et al. 2009, J. Nucl. Mater. 390-391 858

[12] Maier H et al. 2007 J. Nucl. Mater. 363-365 1246-1250

[13] Greuner H et al. 2007 J. Nucl. Mater. 367 1444-1448

[14] Duwe R, Kuehnlein W, Muenstermann H 1995 Fusion Technology 1994355

[15] Thornton J.A. 1977 Ann. Rev. Mater. Sci. 7239

[16] G. Matthews et al. 2009 J. Nucl. Mater. 390-391 934-937

[17] Neu R et al. 2007 Phys. Scr. T138 150

[18] Hirai T et al. 2009 J. of Nucl. Materials 392 40-44 